NBER WORKING PAPER SERIES

PROPERTY RIGHTS, REGULATORY CAPTURE, AND EXPLOITATION OF NATURAL RESOURCES

Christopher Costello

Corbett Grainger

Working Paper 20859

http://www.nber.org/papers/w20859

\author{
NATIONAL BUREAU OF ECONOMIC RESEARCH \\ 1050 Massachusetts Avenue \\ Cambridge, MA 02138 \\ January 2015
}

We are deeply grateful for helpful comments from Wolfram Schlenker, Jennifer Alix-Garcia, Gary Libecap, Robert Deacon, Scott Taylor, Larry Karp, Ray Hilborn, Mike Melnychuk, Steven Gaines, Bruno Nkuiya, John Lynham, Jeffrey Traczynski, and seminar participants at various institutions, including the NBER, University of Hawaii, University of Calgary, the World Congress of Environmental and Resource Economists, the Heartland Workshop at UIUC, and Institute Henri Poincare (Paris). The views expressed herein are those of the authors and do not necessarily reflect the views of the National Bureau of Economic Research.

NBER working papers are circulated for discussion and comment purposes. They have not been peerreviewed or been subject to the review by the NBER Board of Directors that accompanies official NBER publications.

(C) 2015 by Christopher Costello and Corbett Grainger. All rights reserved. Short sections of text, not to exceed two paragraphs, may be quoted without explicit permission provided that full credit, including (C) notice, is given to the source. 
Property Rights, Regulatory Capture, and Exploitation of Natural Resources

Christopher Costello and Corbett Grainger

NBER Working Paper No. 20859

January 2015

JEL No. H23,H41,L2,Q2,Q22

\begin{abstract}
$\underline{\text { ABSTRACT }}$
We study how the strength of property rights to individual extractive firms affects a regulator's choice over exploitation rates for a natural resource. The regulator is modeled as an intermediary between current and future resource harvesters, rather than between producers and consumers, as in the traditional regulatory capture paradigm. When incumbent resource users have weak property rights, they have an incentive to pressure the regulator to allow resource extraction at an inefficiently rapid rate. In contrast, when property rights are strong, this incentive is minimized or eliminated. We build a theoretical model in which different property right institutions can be compared for their incentives to exert influence on the regulator. The main theoretical prediction - that stronger individual property rights will lead the regulator to choose more economically efficient extraction paths - is tested empirically with a novel panel data set from global fisheries. Exploiting the variation in timing of catch share implementation in our panel data, we find that regulators are significantly more conservative in managing resources for which strong individual property rights have been assigned to firms; this is especially pronounced for resources that have been overexploited historically.
\end{abstract}

Christopher Costello

Bren School of Environmental

Science \& Management

University of California, Santa Barbara

Santa Barbara, CA 93106

and NBER

costello@bren.ucsb.edu

Corbett Grainger

Department of Agricultural and Applied Economics

University of Wisconsin, Madison

Madison, WI 53706

http://www.aae.wisc.edu/cagrainger

cagrainger@wisc.edu 


\title{
Property rights, regulatory capture, and exploitation of natural resources*
}

\author{
Christopher Costello ${ }^{\dagger}$ and Corbett Grainger ${ }^{\ddagger}$
}

January 9, 2015

\begin{abstract}
We study how the strength of property rights to individual extractive firms affects a regulator's choice over exploitation rates for a natural resource. The regulator is modeled as an intermediary between current and future resource harvesters, rather than between producers and consumers, as in the traditional regulatory capture paradigm. When incumbent resource users have weak property rights, they have an incentive to pressure the regulator to allow resource extraction at an inefficiently rapid rate. In contrast, when property rights are strong, this incentive is minimized or eliminated. We build a theoretical model in which different property right institutions can be compared for their incentives to exert influence on the regulator. The main theoretical prediction - that stronger individual property rights will lead the regulator to choose more economically efficient extraction paths - is tested empirically with a novel panel data set from global fisheries. Exploiting the variation in timing of catch share implementation in our panel data, we find that regulators are significantly more conservative in managing resources for which strong individual property rights have been assigned to firms; this is especially pronounced for resources that have been overexploited historically.
\end{abstract}

\section{Introduction}

Many natural resources are governed not by the well-studied extremes of open access or sole ownership, but instead by an intermediate case in which a regulator sets extraction caps and a limited number of firms are granted the rights to extract. We focus on two features of these systems: First, because the regulator herself sets the extraction rate, she may be

${ }^{*}$ We are deeply grateful for helpful comments from Wolfram Schlenker, Jennifer Alix-Garcia, Gary Libecap, Robert Deacon, Scott Taylor, Larry Karp, Ray Hilborn, Mike Melnychuk, Steven Gaines, Bruno Nkuiya, John Lynham, Jeffrey Traczynski, and seminar participants at various institutions, including the NBER, University of Hawaii, University of Calgary, the World Congress of Environmental and Resource Economists, the Heartland Workshop at UIUC, and Institute Henri Poincare (Paris).

†Bren School, University of California Santa Barbara; National Bureau of Economic Research. Email: costello@bren.ucsb.edu

${ }_{\ddagger}^{\ddagger}$ Department of Ag. \& Applied Economics, University of Wisconsin - Madison. Email: cagrainger@wisc.edu 
susceptible to the influence of the extraction sector, i.e. to regulatory capture. Second, the strength of property rights allocated to extractive firms may affect their preferred rates of extraction. We derive the equilibrium behavior of the regulator in this setting, and we show how extraction paths will depend on the strength of property rights granted to the harvest sector. We test our theoretical predictions with a novel data set of global fisheries, roughly half of which have implemented policies granting stronger individual property rights over the past several decades. Consistent with our theory, we find that stronger individual property rights lead the regulator to reduce aggregate rates of extraction. The resulting differences in extraction rates have both economic and ecological consequences.

Property right institutions play a central role in shaping incentives and determining economic outcomes including investment, resource use and growth (e.g. Acemoglu and Johnson (2005), Grainger and Costello (2014), and North et al. (2009)). It is well-established that individual owners' behaviors depend on the security of the underlying property rights. Weak property rights can lead to incentives for individual over-exploitation in fisheries (Costello and Kaffine 2008) and forests (Deacon 1995; Deacon 1999), ${ }^{12}$ and land tenure has been shown to affect land use decisions in several settings (Besley 1995; Alston et al. 2000). Despite this evidence, it may be impossible or undesirable to grant sole-ownership over an entire resource stock to a single firm. Large aquifers, highly migratory fish stocks, rights to water in rivers or streams, and atmospheric pollution are just a few examples of resources that are often managed by a regulator who sets an extraction cap affecting a limited set of firms with access rights. Despite the ubiquity of this arrangement, the literature on property rights and natural resources has focused on individual incentives and has largely ignored the role of the regulator in setting the overall extraction rules. ${ }^{3}$

We address two fundamental questions about the effects of property rights institutions on a common pool resource: First, in a theoretical sense, under what conditions does the property right strength to individual firms alter incentives for the regulator setting the extraction policy? And second, is there empirical evidence that property right strength affects the aggregate exploitation chosen by the regulator? Recent work on the effects of rights based management on fishery outcomes (Costello et al. 2008; Grafton et al. 2000; Grainger and Costello 2014; Newell et al. 2005) has been criticized because for most natural resources, it is the regulator, not the individual firms, that determines exploitation rates. This critique calls into question the economist's intuition about the role of property rights in efficient resource use. To our knowledge we are the first to examine the impact of individual property rights on the regulator's choice of resource exploitation rates. We develop a general framework to determine how individual property rights affect the regulator's extraction policy, and when that extraction policy coincides with the social optimum.

Following Karpoff (1987) and others, we take as given that the extractive industry will attempt to influence the regulatory decisions in their favor. Most of the literature on regulatory capture focuses on natural monopolies or industries in which rights are well-defined and per-

\footnotetext{
${ }^{1}$ See Liscow (2013) for a recent counterexample regarding the impact on deforestation.

${ }^{2}$ A noteworthy nuance is introduced by Bohn and Deacon (2000), who delineate conditions under which extraction may be increased or decreased as a result of ownership risk.

${ }^{3}$ While they do not model the influence of industry on a regulator's chosen extraction rate, Homans and Wilen (1997) do examine a setting in which a regulator must respond to entry by firms, typically by shortening the allowable fishing season.
} 
petual (Stigler 1971; Posner 1974; Peltzman 1976). However, in the natural resources sector rights are often not well-defined, are easily disputed, or are granted only temporarily. These differences in property rights will affect an industry's preferred harvest policies. Ultimately, then, the property right designation will affect economic and environmental outcomes.

We build an analytical model in which different property right institutions can be compared. The strength of property rights is modeled as the likelihood that the incumbent's rights will be revoked; this allows us to explore a wide spectrum of possible institutions, from open access to perfectly secure perpetual rights to a resource. We show how harvesters' preferred extraction policies depend critically on the property right institution. Because regulators are subject to industry influence, regulatory outcomes are expected to depend on property right institutions.

Our results show that when property rights to the resource are strong, the regulator's choice (which is the product of resource harvesters' influence) coincides with the public interest. However, when property rights to the resource are weak, the regulator's choice leads to overexploitation. This suggests that the resulting extraction level is closer to the socially-optimal extraction level when rights to the resource are strong. This has broader implications for resource policy design and understanding economic outcomes as shaped by property rights institutions.

Our model separates the regulator's problem from the extraction path that individuals would choose. We show that when property rights are more secure, individuals would lobby for a lower exploitation rate, but when property rights are weak individuals would lobby for short-run gains and overexploitation. The theoretical prediction leads to an empirical test using a novel dataset of historical stock assessments from large, commercial fisheries. We exploit differences in the timing of Catch Share adoption in order to estimate the impact of property rights on aggregate harvest policy. A strength of our empirical approach is that we can directly estimate policy functions pursued by the regulator, where the exploitation rate is a function of the property rights institution underlying the resource, the state of the resource (i.e. the stock of fish) and fishery-specific and year-specific characteristics. Our estimates are consistent with the analytical model's predictions, and suggest that ceteris paribus, regulators are more conservative when resource harvesters have secure rights.

\section{Resource Dynamics and Regulatory Capture}

In this section we develop a simple dynamic representation of the micro problem facing an incumbent harvesting sector and the macro problem facing the regulator. We begin by observing that property rights, and the manner in which they are strengthened or weakened, are strongly context-dependent. A property right in this context has several characteristics, including exclusivity, security, duration, and transferability. Considered in this light, the strength of a property right may be infringed in any one of several dimensions. For example, the duration or tenure of a property right often differs across institutions (see Costello and Kaffine (2008) for a theoretical analysis of incentives under limited tenure), as with forestry (Boscolo and Vincent 2000), wildlife management areas, and some fisheries. But often the duration is not made explicit; rather, harvesters must cope with uncertainty about the longevity of their rights. An extreme case is open access, in which one's ownership 
horizon can be regarded as infinitesimally short. Less extreme examples include ownership in many developing countries which lack rule of law so owners face a perpetual likelihood of revocation (by government or indeed by rival owners). On the other hand, a prevalent type of management is limited entry, or "regulated open access" (Homans and Wilen 1997), which involves rights that may be revoked or limited at any time. ${ }^{4}$ Even when rights are explicit, there may be differences in the probability of revocation across jurisdictions.

In our model it is the regulator, not the individual harvesters, who determines the aggregate harvest. Institutional regimes are regarded as exogenous to the regulator, though in practice the regulator may have some influence the management type (i.e. property rights vs. limited entry vs. open access), the access rights, and/or the reallocation process. Treating management type as exogenous, the regulator is charged with determining how much of the resource may be harvested during a specified length of time. This accords with how most natural resources are managed. For example, in a fishery, the regulator typically sets the total allowable catch (the TAC), which places a quota on total harvest. How the regulator sets the TAC varies across fisheries, but in the United States this involves several steps. Regional management councils, which are typically elected by fishery stakeholders, appoint scientific committees to study the health of the stock through so-called stock assessments. Stock assessments combine sampling and ecosystem models to estimate the biomass as well as a reference point such as the "maximum sustained yield" biomass level (i.e. the biomass level associated with the highest sustainable harvest rate for that fishery's biological characteristics). Given estimates of biomass, the scientific committee recommends an exploitation rate to the management council. Councils then typically have meetings, both public and private, to set the exploitation rate for the next year (or sometimes several years). During this process, stakeholders provide comments to the regulator, and often the regulator's decision strays from the scientific committee's recommendation.

Our theoretical treatment and empirical application rest on one key assumption regarding regulatory capture. The key assumption is that (at least in natural resource sectors) the extraction industry will always have a pathway to influence regulatory decisions about the extraction rate. That is, regardless of property right strength, the regulator is susceptible to influence by the extractive industry. Our theoretical analysis then establishes that the strength of property rights to the extractive industry will affect what they attempt to influence the regulator to do. In particular, we show that extractors with strong property rights have a incentive to lobby for a more conservative (i.e. lower) harvest rate than do extractors with weak property rights.

While no comprehensive analysis has been undertaken on these issues, anecdotes abound that support our basic story. First, we note that it is commonplace for the regulator, or more accurately the council with regulatory power, to include owners of large fishing firms (among other industry members) on the council. Okey (2003) surveys the regulatory councils in the United States and finds that roughly half of the appointed voting members represent commercial fishing interests. For evidence supporting our assumption of ubiquitous industry influence that extends even beyond their formal membership on councils, all one has to do is attend (or inspect the minutes of) a public meeting during which the regulator solicits

\footnotetext{
${ }^{4}$ In addition to revoking an individual's rights, the regulator could increase the set of individuals with access if rights are not well-defined.
} 
public comment over extraction policy. ${ }^{5}$

Thus, our theoretical analysis takes as given that pathways exist through which an extractive industry can influence regulatory decisions over extraction. Within that framework, our theoretical analysis will conclude that regulations desired by the industry will hinge critically on the property right structure. This finding also has empirical grounding. For example, in the US surfclam and ocean quahog fishery (for which a Catch Share (i.e. a strong property right) was implemented in 1990), industry pressure was clearly to raise the catch limit before 1990 and clearly to decrease the catch limit after (New England Fishery Management Council 1984; Mid-Atlantic Fishery Management Council 1985; Mid-Atlantic Fishery Management Council 2012). ${ }^{6}$ Gauvin et al. (1994) demonstrate a very similar dynamic, in which industry lobbies for higher catch before Catch Shares and for lower catch after Catch Shares, in the South Atlantic wreckfish fishery (which switched to Catch Shares in 1992). And a widely-studied fishery in New Zealand (the rock lobster fishery) illustrates the industry support for reductions in catch under Catch Shares (Grafton et al. 2006; Leal et al. 2005; Hilborn et al. 2005). These are just a few of the hundreds of anecdotes or case studies that support the assumptions underlying our theoretical and empirical analysis.

We thus assume that industry will exert pressure on the regulator, regardless of the strength of individual property rights. But because the incumbent industry's rights may be insecure, the regulator may also account for the effects of her decisions on the future owners' utilities, i.e. future potential owners may exert some pressure (albeit less effective) on the regulator. In this way the regulator acts as an intermediary between incumbent and future harvesters. The regulator's problem may therefore not coincide with the social planner's problem, as the regulator can be influenced by different stakeholders in the process. Nor does the regulator's problem coincide with the incumbent harvester's problem (except in a limiting case). In this sense, the regulator's choice may differ from the socially-optimal harvest rate and from the rate that would be chosen by the incumbent. That is, capture of the regulator will result in a policy that is somehow a balance between what would be optimal for incumbent harvesters and what would be optimal for the public at large. Our model predicts that the divergence between a capture regulator's decision and the socially optimal decision will be largest when property rights to the resource are weak.

We abstract away from the precise manner in which property rights are "stronger" or "weaker" by representing the strength of property rights with a single parameter. ${ }^{7}$ We assume that incumbent harvesters face the possibility that his resource ownership will be revoked

\footnotetext{
${ }^{5}$ In US fisheries, these are the meetings of the fishery management councils. Fishermen and owners of fishing companies routinely attend council meetings and vocally advocate for their preferred harvest quota. Other countries, and other industries, have similar structures.

${ }^{6}$ In 1984 (pre-Catch Share transition) there was broad industry support for Amendment 4 (later Amendment 6), which changed the upper bound of the New England area annual surf clam quota from 100,000 bushels to 200,000 bushels. In 2013 (post-Catch Share transition) several quota shareholders requested a decrease in the quota. For example, one submitted comment states: "I am writing you as a stockholder of a corporation which owns rights to surf clam and quahog allocations in the Mid-Atlantic region; that corporation being Adriatic, Inc. I am writing to request that the total permitted catch be reduced...Please consider reducing the annual harvest limits... so those of us that own the rights can get some economic benefit from them."

${ }^{7}$ Another approach from resource economics is in Arnason (2012), who constructs an index based on several property right characteristics.
} 
in the future; the higher is this probability, the weaker is the property right. Given this undermining of property right strength, the incumbent will exert pressure on the regulator to achieve her own private objective, which we assume is to maximize expected profit over the duration of his tenure. The regulator, on the other hand, must simultaneously account for the welfare of current and future extractors. If any one group is excessively favored, the regulator faces her own retribution.

\subsection{Resource user's objective}

Let the resource stock at time $t$ (e.g. biomass) be given by $b(t)$, and the harvest rate be given by $h(t)$. The instantaneous payoff may depend both on resource stock and on harvest, as follows:

$$
\pi(b, h)=R(h)-c(b)-k(b) h
$$

This expression allows payoffs to depend positively on both stock and harvest, and allows an interaction between those variables. In particular, we will assume that revenue has the properties $R_{h}>0$ and $R_{h h}<0$ (for example, reflecting a downward-sloping demand), that harvest-independent cost has the properties $c_{b}<0$ and $c_{b b}>0$, that per unit harvest cost has the properties $k_{b}<0$ and $k_{b b}<0$. Finally, we will assume that the payoff is strictly increasing in harvest (so $\left.R^{\prime}-c>0\right){ }^{8}$

As an initial benchmark, with complete and secure property rights, the objective function of the social planner or sole resource owner is given by:

$$
\max _{h(t)} \int_{0}^{\infty} \pi(b(t), h(t)) e^{-r t} d t
$$

where $r$ is the discount rate. For a renewable resource, this is subject to the familiar equation of motion: $\dot{b}=g(b)-h,{ }^{9}$ where $g$ has an inverted $U$ shape and $g^{\prime \prime}(b)<0$. It will become convenient to express Equation 2 as the continuous time dynamic programming equation, or Hamilton-Jacobi-Bellman (HJB) Equation, as follows:

$$
r V(b)=\max _{h}\left\{\pi(b, h)+V^{\prime}(b)[g(b)-h]\right\}
$$

where $V(b)$ is a value function. Equation 3 has as its solution an optimal feedback control rule, $h^{*}(b)$. If that rule is followed in perpetuity, the present value of the resource will be maximized.

While this will turn out to be a limiting case of the problem we study, it is not the typical case because in our problem, the incumbent resource user faces an uncertain future. In particular, we assume that the incumbent harvester faces a perpetual chance that his rights will be revoked without compensation. Let the hazard rate be given by $\theta$, so higher values of $\theta$ reflect a less secure property right. We will assume that the parameter $\theta$ is fixed

\footnotetext{
${ }^{8}$ These conditions imply $\pi_{h}>0, \pi_{b}>0, \pi_{h h}<0, \pi_{b b}<0, \pi_{h h}<0, \pi_{b h}>0, \pi_{b b h}<0$, and $\pi_{b h h}=0$, which will be invoked later.

${ }^{9}$ We have suppressed time in these functions for expositional ease, except where necessary.
} 
and exogenous. ${ }^{10}$ Under this setup, HJB function facing the incumbent is:

$$
(r+\theta) V(b)=\max _{h}\left\{\pi(b, h)+V^{\prime}(b)[g(b)-h]\right\}
$$

which is easily verified because the hazard rate $\theta$ enters the problem in a manner identical to the discount rate, so the two rates are simply added together. ${ }^{11}$ When the incumbent's rights are revoked, they are granted to a subsequent user, who himself faces an insecure property right given by the hazard rate $\theta$. Thus, once an owner is granted the harvest right, he has the optimality condition given by Equation 4 .

\subsection{Regulator's objective}

In many natural resources, exploitation rates are not directly chosen by the harvesting sector. Instead, a regulator is charged with setting the extraction rate, presumably to protect future generations from over-extraction by the incumbent harvester. Thus we incorporate a regulator into the model above. Here, the (current and future) resource users influence the regulator, but the regulator determines the extraction rate. Next we derive the regulator's objective.

What motivates the regulator to choose a harvest policy? And on what will that harvest policy depend? We will assume that the regulator is entirely motivated by the influence of her current and future constituents. We will allow for the possibility that current resource users have a stronger influence on regulatory decisions than do future resource users. We assume that the regulator wishes to maximize a simple weighted objective function where the weights represent the relative influence of subsequent extractors. Denote by $\gamma \leq 1$ the weight placed by the regulator on the subsequent extractor's welfare. For example, if $\gamma=.5$ then the regulator will consider the welfare of the subsequent owner, but only gives it half the weight of the incumbent's welfare. As $\gamma$ approaches one, the influence of subsequent owners approaches that of the incumbent.

The problem can thus be summarized as follows. An incumbent harvester exerts pressure on the regulator to achieve the objective given by Equation 4. That harvester maintains the same objective, and presumably the same influence over the regulator, until the resource is granted to a new owner. All the while, the regulator must consider the fact that the subsequent resource owner (and indeed those that follow) will inherit a resource stock that is the product of her current policy. If she allows too much extraction in the current period, thus favoring the incumbent, future resource owners are disadvantaged (and will exert pressure to reduce current extraction). Conversely, if she favors future owners too much, e.g. by reducing current harvest to build up resource stocks, then the current owner is disadvantaged (and will exert pressure to increase current extraction). Wanting to balance the welfare of the incumbent with the welfare of the next owner (down-weighted by $\gamma$ if $\gamma<1$ ), and indeed the

\footnotetext{
${ }^{10}$ It is common, for example, for the general property right structure governing natural resource use to be set at a higher political level than are the decisions over annual extraction rates. In the empirical example that follows (fisheries) this will often be the case. In the United States the Department of Commerce sets overall policy on property rights and governance of fisheries, while the regional fishery management councils determine annual quotas, or exploitation rates.

${ }^{11}$ The probability that the right is lost by time $t$ is: $1-e^{-\theta t}$.
} 
welfare of the owner after that (this time, down-weighted by $\gamma^{2}$ ), etc., the regulator must solve a complicated dynamic problem. Framing this as a dynamic programming equation over a short interval $[0, \tau]$, we can gain traction on the regulator's policy decision, as follows: ${ }^{12}$

$$
\begin{aligned}
V(b)=\max _{h}\{\pi(b, h) \tau & +(1-r \tau)(1-\theta \tau) V(b+(g(b)-h) \tau) \\
& +(1-r \tau) \theta \tau \gamma V(b+(g(b)-h) \tau)+o(\tau)\} .
\end{aligned}
$$

The dynamic programming Equation 7 expresses the regulator's maximized payoff from choosing harvest, $h$, given a resource stock, $b$. The first term on the right hand side is the payoff she will obtain over the (short) time interval $[0, \tau]$. The second term on the right hand side expresses the discounted continuation payoff when the property right is retained (this occurs with probability $(1-\theta \tau)$ ). The third term on the right hand side expresses the discounted continuation payoff when the property right is revoked (this occurs with probability $\theta \tau$ ), recognizing that in that event, the future utility is downweighted by $\gamma$. Collecting terms provides the following:

$$
V(b)=\max _{h}\{\pi(b, h) \tau+(1-r \tau)(1-\theta \tau+\theta \tau \gamma) V(b+[g(b)-h] \tau)+o(\tau)\}
$$

Taking a first order Taylor series expansion, and noting terms with $\tau^{2}$ are $o(\tau)$, gives:

$$
V(b)=\max _{h}\left\{\pi(b, h) \tau+[1-r \tau-\theta \tau+\gamma \theta \tau]\left[V(b)+V^{\prime}(b)[g(b)-h] \tau\right]+o(\tau)\right\}
$$

Collecting terms, dividing by the time interval $\tau$, and taking the limit as $\tau \rightarrow 0$ provides a derivation of the HJB equation for the captured fishery regulator:

$$
\delta V(b)=\max _{h}\left\{\pi(b, h)+V^{\prime}(b)[g(b)-h]\right\}
$$

where $\delta \equiv r+\theta-\gamma \theta$ can be interpreted as the "captured regulator's discount rate." This gives rise to our first set of theoretical predictions:

Proposition 1. (a) The captured regulator's problem is identical to the sole-owner's problem, but with a higher discount rate ( $\delta$ rather than $r$ ).

(b) The captured regulator's discount rate is $\delta \equiv r+\theta-\gamma \theta$. She discounts at a higher rate if: (1) The original discount rate is higher, (2) the property right is weaker, and/or (3) she assigns lower weight to future resource owners' utility.

Proof. Claim (a) is confirmed by comparing Equations 10 and 3. Claim (b) is confirmed by $\frac{d \delta}{d r}=1>0, \frac{d \delta}{d \theta}=1-\gamma \geq 0$, and $\frac{d \delta}{d \gamma}=-\theta \leq 0$.

\footnotetext{
${ }^{12}$ We will make use of the following first-order approximations:

$$
\begin{aligned}
1-r \tau+o(\tau) & =e^{-r \tau} \\
\theta \tau-o(\tau) & =1-e^{-\theta \tau}
\end{aligned}
$$

where higher-order-terms $o(t)$ have: $\lim _{\tau \rightarrow 0} \frac{o(\tau)}{\tau}=0$.
} 
Proposition 1 will prove quite useful in what follows. Despite the complexity of the captured regulator's problem, the dynamic policy problem faced by the captured regulator is formally identical to the familiar dynamic policy problem faced by a sole owner, except that the two problems have different discount rates. While the sole owner (whose rights extend in perpetuity) must account only for the original discount rate itself $(r)$, the captured regulator must also account for the stochastic timing of the revocation of rights (via the hazard rate $\theta$ ) and the weight she assigns to future owners of the resource (via the parameter $\gamma$ ). These three parameters combine to form the captured regulator's effective discount rate, $\delta \equiv r+\theta-\gamma \theta$. Naturally, the higher is the original discount rate $(r)$, the less emphasis the captured regulator will give to the future. But we have also shown that the captured regulator places less weight on the future when the property right is weakened ( $\theta$ increases) or the weight on future generations' utility is decreased ( $\gamma$ decreases). A weaker property right suggests a higher probability of revocation in the short-run, which causes the regulator to favor current harvest. ${ }^{13}$ It is through a completely different mechanism that lower $\gamma$ causes the regulator to discount at a higher rate. In that case, less weight is being given to future owners, so the captured regulator favors the current generation. All of these effects appear mathematically simply as increases in the captured regulator's effective discount rate.

A few special cases are worth noting. First, if the regulator is equally influenced by incumbents and all future harvesters in perpetuity (so $\gamma=1)$ the captured regulator's discount rate equals the social planner's discount rate. This is intuitive: Even if property rights are insecure, the regulator must account equally for current and future generations, so no increase in impatience is warranted. Second, if property rights are very strong (so the hazard rate is very low - in the limit $\theta=0$ ), the regulator is certain of property right retention by the incumbent, so the captured regulator's discount rate equals the social planner's discount rate (even if she assigns a low value to $\gamma$ ). This result also makes sense. Even if the regulator assigns very little weight to future generations, provided the property right to the current generation is sufficiently strong, the regulator will not increase impatience.

Under this setup, the regulator's problem, which embeds the welfare of the incumbent property right holder and all future property right holders (who exert some influence over the current regulator), has exactly the same functional form as the problem facing the perpetual property right holder (i.e. Equation 10 has the same form as Equation 3). The only difference is the interpretation of the discount rate. The next section will build on these insights to derive the properties of the policy function pursued by the captured regulator.

\section{Property Rights and the Consequences of Regula- tory Capture}

Here we employ the dynamic model above to analyze the consequences of regulatory capture. In particular, we would like to examine the interplay between the strength of property rights (represented in our model by $\theta$ ), the weight the regulator places on future resource owners' welfare (captured by $\gamma$ ), and how they jointly determine the captured regulator's extraction

\footnotetext{
${ }^{13}$ Intuitively, this result is weakened as the regulator places greater weight on future generations: $\frac{d^{2} \delta}{d \theta d \gamma}=$ $-1<0$. In the extreme, when $\gamma=1$, there is no effect of $\theta$ on $\delta$.
} 
path.

The regulator's problem (given by Equation 10) has a solution of the form: $h^{*}(b ; \delta)$, which is time-independent. In other words, the regulator will choose a single policy function ${ }^{14}$ that can be followed every period. ${ }^{15}$ That optimized policy function maps the current level of the resource stock $(b)$ into harvest $(h)$; when that policy function is followed every period, the captured regulator's objective is optimized, so she perfectly balances the objectives of all current and future constituents who exert influence on her. In general, that optimal policy function will depend on the discount rate $\delta \equiv r+\theta-\gamma \theta$, and thus on property right hazard $\theta$. The regulator facing the problem in Equation 10 obtains the following current value Hamiltonian:

$$
H^{c}(b, h, \mu)=\pi(b, h)+\mu(g(b)-h)
$$

for shadow value, $\mu$. Invoking the Maximum Principle yields two useful equations which define the optimal movement of $b$ and $h$ over time:

$$
\begin{aligned}
& \dot{b}=g(b)-h \\
& \dot{h}=\frac{\pi_{h}\left(\delta-g_{b}\right)-\pi_{b}-\pi_{h b} \dot{b}}{\pi_{h h}}
\end{aligned}
$$

Equation 12 defines the dynamics of the resource stock along the optimal trajectory. Equation 13 is the Euler Equation for this problem, and, together with Equation 12, defines the optimal dynamics of harvest. Equations 12 and 13 can be used to derive the properties of the steady state of this system, and, more importantly for our analysis, to derive the optimal policy function itself. In particular, we would like to determine what can be said about the optimal policy function's dependence on the discount rate, $\delta$. The first useful result is that for any $\delta$, the policy function is upward-sloping:

Lemma 1. The optimal feedback control rule $h^{*}(b)$ is upward-sloping; it cuts the biological steady state curve $g(b)$ from below.

Proof. First we show that the $\dot{h}=0$ isocline, given by the Euler Equation, is upward-sloping in the vicinity of the steady state. Setting Equation 13 equal to 0, gives

$$
\pi_{h}\left(\delta-g_{b}\right)-\pi_{b}-\pi_{h b} \dot{b}=0
$$

Totally differentiating with respect to $b$ and $h$, and invoking the Implicit Function Theorem, gives the slope of the $\dot{h}=0$ isocline, as follows:

$$
\left.\frac{d h}{d b}\right|_{\dot{h}=0}=\frac{\pi_{h b}\left(\delta-g_{b}\right)+g_{b b} \pi_{h}+\pi_{b b}+\pi_{h b b} \dot{b}+\pi_{h b} \dot{b}_{b}}{\pi_{h h}\left(\delta-g_{b}\right)}
$$

By Equation 14, and below $g(b)$ (so $\dot{b}>0$ ), it is easy to see that $\delta-g_{b}>0$. The only ambiguous term is $\dot{b}_{b}$, which is clearly negative at the steady state. Thus, in the vicinity

\footnotetext{
${ }^{14}$ I.e. a feedback control rule.

${ }^{15}$ One interesting consequence of Equation 10 is that it is optimal for the captured regulator to follow the same feedback control rule at all times, regardless of who happens to be the incumbent or how long that incumbent has held the right.
} 
Figure 1: Phase-Plane Diagram with Optimal Policy Function, $h^{*}(b)$

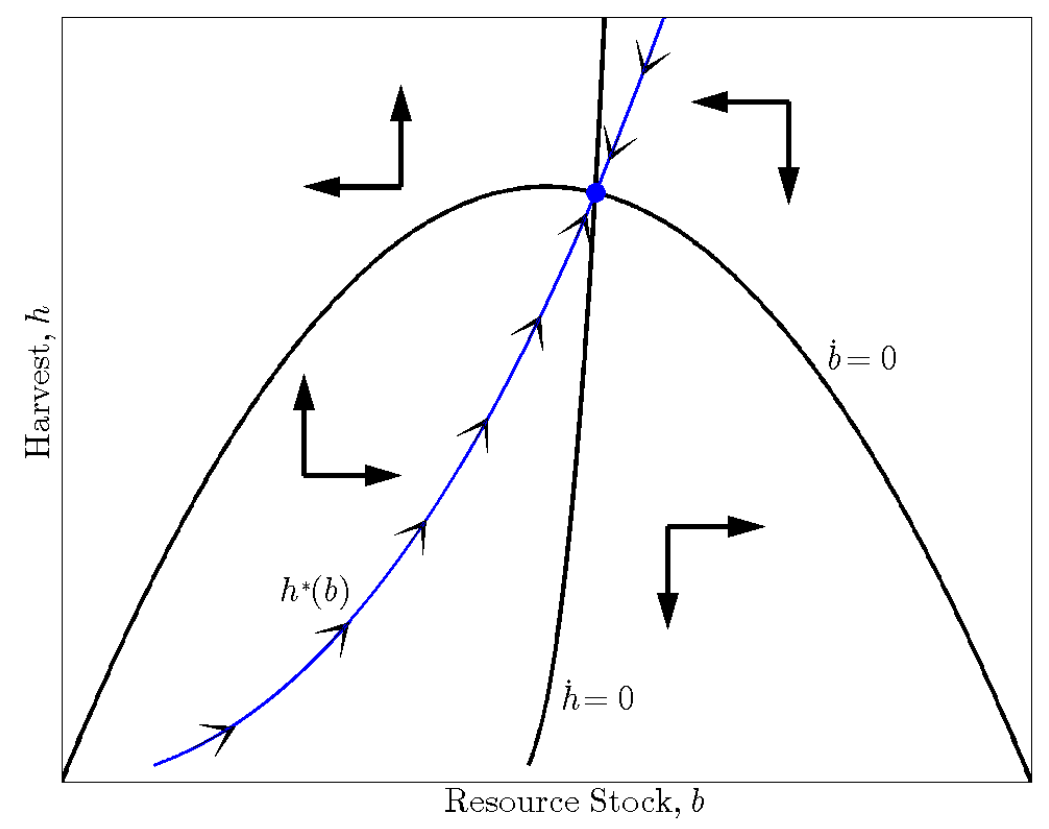

of the steady state both the numerator and denominator of 15 are negative, so the $\dot{h}=0$ isocline is increasing.

The second step in the proof is to show that the $h^{*}(b)$ is also upward-sloping. To do so, we derive the directional arrows (see Figure 1). The arrows for resource stock $(b)$ are calculated as follows:

$$
\left.\frac{d \dot{b}}{d h}\right|_{\dot{b}=0}=-1<0
$$

So the arrows point left above the $g(b)$ curve and point right below the $g(b)$ curve. The directional arrows for extraction $(h)$ are found as follows:

$$
\left.\frac{d \dot{h}}{d h}\right|_{\dot{h}=0}=\frac{\pi_{h h}\left(\pi_{h h}\left(\delta-g_{b}\right)-\pi_{h b}-\pi_{h h b} \dot{b}-\dot{b}_{h} \pi_{h b}\right)-\left(\pi_{h}\left(\delta-g_{b}\right)-\pi_{b}-\pi_{h b} \dot{b}\right) \pi_{h h h}}{\pi_{h h}^{2}}
$$

Invoking the conditions $\pi_{h h b}=0, \dot{h}=0$, and $\dot{b}_{h}=-1$, this expression is unambiguously positive. Above the $\dot{h}=0$ isocline the arrows point up and below the $\dot{h}=0$ isocline, the arrows point down. In the isosector above $\dot{h}=0$ and below $\dot{b}=0$, we find that $\dot{b}>0$ and $\dot{h}>0$. In the isosector above $\dot{b}=0$ and below $\dot{h}=0$, we find that $\dot{b}<0$ and $\dot{h}<0$. Since $\frac{d h}{d b}=\frac{\dot{h}}{b}$, we find that the policy function is upward-sloping and cuts $g(b)$ from below.

Lemma 1 provides an intuitive result: a larger resource stock calls for a higher optimal extraction rate. The full phase plane for this problem is shown in Figure $1 .{ }^{16}$ Consistent

\footnotetext{
${ }^{16}$ Figure 1 is not a stylized figure, it is produced from a numerical example that adheres to the conditions spelled out above.
} 
with Lemma 1 the $\dot{h}=0$ isocline has a positive slope, $h^{*}(b)$ is increasing, and cuts $\dot{b}=0$ from below. While Lemma 1 holds for any discount rate, $\delta$, we are primarily interested in how $\delta$ influences the policy function itself. An interesting initial question is how the steady state depends on $\delta$, which we summarize as follows:

Lemma 2. A larger value of $\delta$ delivers a lower steady state stock level (b). Whether it delivers a lower, or higher, steady state harvest rate $(h)$ depends on whether the steady state is to the left or right of the maximum value of $g(b)$.

Proof. The $\dot{b}=0$ isocline is independent of $\delta$ and is therefore unchanged as $\delta$ increases. The $\dot{h}=0$ isocline is a function of $\delta$. In steady state $\dot{h}=\dot{b}=0$ so $\pi_{h}\left(\delta-g_{b}\right)-\pi_{b}=0$. Totally differentiating this expression with respect to $b$ and $\delta$ and using the Implicit Function Theorem delivers the desired result:

$$
\left.\frac{d b}{d \delta}\right|_{\dot{h}=\dot{b}=0}=\frac{\pi_{h}}{-\pi_{h b}\left(\delta-g_{b}\right)+g_{b b} \pi_{h}+\pi_{b b}}
$$

which has a positive numerator and negative denominator, so a larger discount rate unambiguously reduces the steady state resource stock. If the steady state level of $b$ happens to be to the right of the maximum of $g(b)$, then the increased discount rate will increase the steady state level of harvest. If the steady state happens to be left of the maximum, then the opposite result is obtained.

Lemma 2 seems to accord with economic intuition: a larger discount rate favors present extraction over future extraction, so we would expect a lower steady state stock. But whether increasing the discount rate increases the harvest rate along the entire optimal policy function is a more nuanced question. In the framework presented above, we find an unambiguous answer, summarized as our main theoretical result:

Proposition 2. A larger discount rate results in a higher optimal extraction rate for any level of stock: $\frac{\partial h^{*}(b)}{\partial \delta}>0$.

Proof. We proceed by contradiction. Consider two discount rates, $\delta_{L}<\delta_{H}$, with corresponding optimal policy functions $h^{*}\left(b ; \delta_{L}\right)$ and $h^{*}\left(b ; \delta_{H}\right)$. Invoking Lemmas 1 and 2 , suppose for some stock, a higher value of $\delta$ did not result in a higher optimal extraction rate. Then it must be the case that the policy functions cross. Let the crossing occur at point $(h, b)=(\hat{h}, \hat{b})$, at which point: $h^{*}\left(\hat{b} ; \delta_{L}\right)=h^{*}\left(\hat{b} ; \delta_{H}\right)$. The crossing $(\hat{h}, \hat{b})$ can occur either to the left or the right of the steady state; we consider each case in turn.

If the crossing occurs to the left of the steady state, then $h^{*}\left(\hat{b} ; \delta_{H}\right)$ must be steeper than $h^{*}\left(\hat{b} ; \delta_{L}\right)$, i.e.

$$
\left.\frac{d h^{*}}{d b}\right|_{\hat{h}, \hat{b}, \delta_{H}}=\left.\frac{\dot{h}}{\dot{b}}\right|_{\hat{h}, \hat{b}, \delta_{H}}>\left.\frac{d h^{*}}{d b}\right|_{\hat{h}, \hat{b}, \delta_{L}}=\left.\frac{\dot{h}}{\dot{b}}\right|_{\hat{h}, \hat{b}, \delta_{L}}
$$

Invoking Equations 12 and 13, this inequality becomes:

$$
\frac{\pi_{h}\left(\delta_{H}-g_{b}\right)-\pi_{b}-\pi_{h b}(g-h)}{\pi_{h h}(g-h)}>\frac{\pi_{h}\left(\delta_{L}-g_{b}\right)-\pi_{b}-\pi_{h b}(g-h)}{\pi_{h h}(g-h)}
$$

And after simplifying (and recognizing that $g-h>0$ in this region), this implies $\delta_{H}<\delta_{L}$ which delivers the contradiction. If the crossing occurs to the right of the steady state, then 
Figure 2: Captured Regulator's Policy Function for Two Different Discount Rates

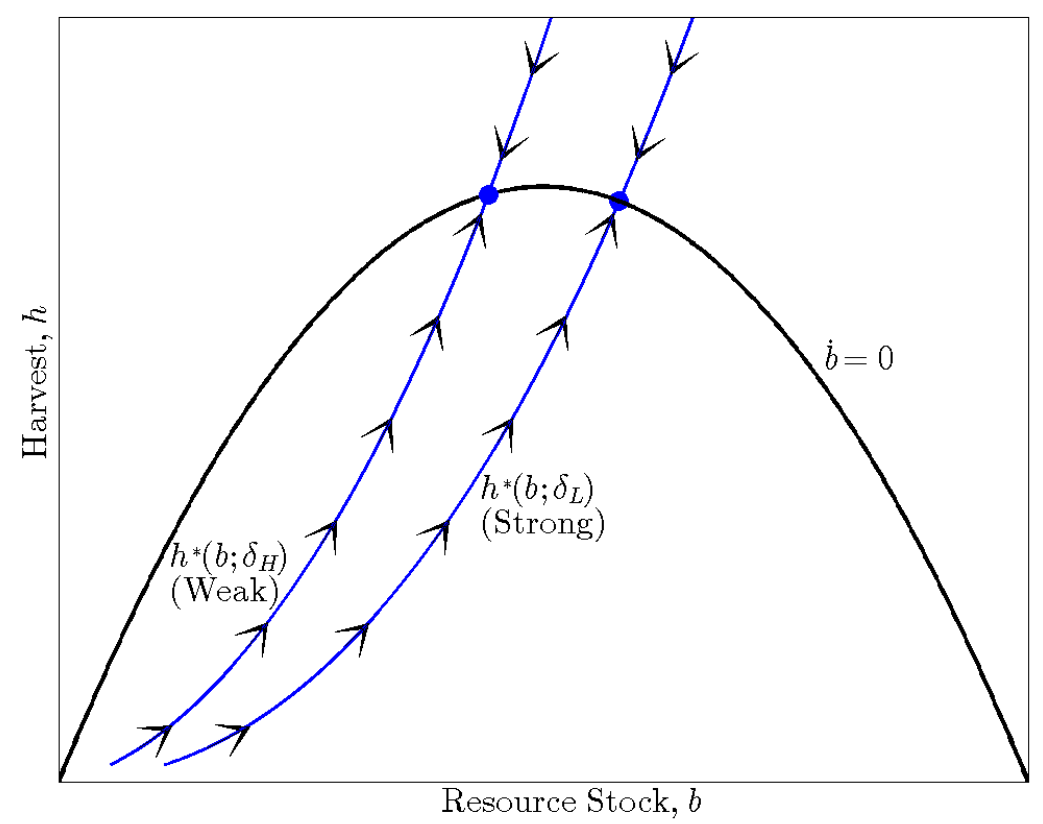

Notes: The phase plane shows the captured regulator's policy function for two different discount rates, $\delta_{H}>\delta_{L}$. Strong property rights are indicated by $\delta_{L}$. Weak property rights are indicated by $\delta_{H}$.

$h^{*}\left(\hat{b} ; \delta_{H}\right)$ must be shallower than $h^{*}\left(\hat{b} ; \delta_{L}\right)$. Following the procedure above (and recognizing that $g-h<0$ in this region), we obtain the contradiction.

Proposition 2 provides a powerful and quite general result: for any stock level inherited by the regulator at time $t$, a higher discount rate results in a higher level of extraction. While this result certainly holds in steady state, Proposition 2 shows that this also holds out of steady state, given any biomass level. The optimal policy for a captured regulator is shown in Figure 2 for two different discount rates, $\delta_{H}>\delta_{L}$. Consistent with Proposition 2, a higher discount rate leads to a higher extraction rate for any level of resource stock.

Recall that weaker property rights to the incumbent industry translated into a high capture adjusted discount rate for the regulator. Viewed in that light, Proposition 2 gives rise to an empirically-testable hypothesis:

Corollary 1. A stronger property right (i.e. lower $\theta$ ) leads to a lower harvest rate for any level of resource stock.

Proof. $\frac{d \delta}{d \theta}=1-\gamma>0$, so a decrease in $\theta$ causes a decrease in the discount rate $(\delta)$, and by Proposition 2, this decreases the harvest rate for any level of resource stock.

Our main empirical analysis will formally test Corollary 1 using a dataset from global fisheries. The fact that Corollary 1 holds for any resource stock will become particularly relevant empirically. Our data on global fisheries suggest that few, if any, stocks are in 
steady state. Thus, we will estimate the entire policy function (i.e. the out-of-steady-state policy choice made by regulators) and ask, in accordance with Corollary 1, whether the policy function depends on the strength of property rights.

\section{An Application to Global Fisheries}

The analytical model developed thus far generates a clear set of predictions that we now test empirically using data on exploitation rates and resource stocks. To do so we leverage differences in property rights over space and time for 178 of the world's largest commercial fisheries. These fisheries are all regulated, in that they have aggregate harvest quotas set by a regulatory body. Also consistent with our theoretical treatment, the durability of the underlying property rights in these fisheries varies dramatically. Some fish stocks are managed by regulated open access, where there may be constraints on entry (e.g. restricting access to domestic vessels only, or where there is a limit on the total number of licenses), but where there are no individual property rights to the resource or its flow. On the opposite end of the spectrum are management regimes with secure, transferable property rights over harvest shares, with many fisheries falling somewhere in between. This variation in property right institutions over space and time will allow us to test whether the strength of property rights has a measurable effect on the regulator's chosen exploitation rate.

To facilitate the empirical test, we adopt a binary measure of property right strength. Fisheries with a Catch Share allocated to individual firms or vessels are regarded as having strong property rights; fisheries that lack Catch Shares are regarded as having weak rights. The term "Catch Share" is a catch-all for a suite of management approaches such as individual transferable quotas (ITQs), spatially delineated individual property rights, and formal fishery cooperatives. ${ }^{17}$ The most common form of Catch Share (in our dataset and in the world) is the ITQ, which allocates a share of the overall harvest (the quota) in a fishery and time period to individual fishermen. Rights are then defined as a share (i.e. a percentage) of the annual harvest quota for that management area and year. In practice the implementation of this type of management varies, with some Catch Share fisheries placing different restrictions on ownership and/or transferability, ${ }^{18}$ but for purposes of this paper, we abstract away from those differences and categorize each fishery in each year as being either a "Catch Share" or a "non-Catch Share." We then test the main prediction of our analytical model, namely: do Catch Shares lead to lower exploitation rates, even in fisheries already managed by a fishery regulator?

\subsection{Data Overview}

While directly testing for the extent of capture is not possible with our data, we note that the assumption that the regulators are captured coincides with anecdotal evidence and with prominent case studies (Johnson and Libecap 1982; Karpoff 1987). Fishermen and industry

\footnotetext{
${ }^{17}$ We adopt the classifications of Catch Shares laid out by Environmental Defense Fund (EDF). For the most part, our categorizations also align with those in Melnychuk et al. (2012). Details are available in an Appendix from the authors.

${ }^{18}$ See Grainger and Parker (2013) for a discussion of the impacts of such restrictions.
} 
representatives routinely sit on management councils, and the regulatory bodies charged with choosing the total harvest quota are often composed largely of current or former fishermen; this is the case for both Catch Share and non-Catch Share fisheries. It is reasonable to assume that there is ample scope for influence of fishermen on fishery regulators across the full spectrum of property right strengths.

We are most interested in a direct test of Corollary 1 - that controlling for the stock of fish, exploitation rates should be lower when underlying property rights are strong. We reiterate that this is a test of the regulator's choice of the harvest policy, in contrast to previous studies, which have focused on the impact of property rights on extraction decisions made by individual firms. To test this, we use a unique dataset that includes both exploitation rates and biomass estimates from historical fishery stock assessments. The stock assessment data come from the RAM II database, maintained at the University of Washington. The data in this study include 178 large, commercially important fisheries from 27 large marine ecosystems around the world.

Over the time period in our analysis, these fisheries are all data-rich, regulated fisheries. The panel data contain annual fishery-level observations for historical exploitation and biomass. Both the harvest and biomass are defined relative to those parameter values under "maximum sustained yield" (which come from surplus production models of the fishery). The two main variables of interest are relative fishing mortality ${ }^{19}$ for fishery $i$ in year $t\left(f_{i t} \equiv \frac{F_{i t}}{F_{i}^{M S Y}}\right)$ and relative biomass $\left(b_{i t} \equiv \frac{B_{i t}}{B_{i}^{M S Y}}\right) .{ }^{20}$ We normalize harvest by maximum sustained yield according to the following identity: ${ }^{21}$

$$
h_{i t} \equiv \frac{H_{i t}}{M S Y}=\frac{F_{i t}}{F_{i}^{M S Y}} \frac{B_{i t}}{B_{i}^{M S Y}} \equiv f_{i t} b_{i t}
$$

This normalization allows us to examine actual expoitation (i.e. the realized harvest) to a reference point for that fishery, namely the maximum sustained yield (MSY). To test our theory regarding the impact of individual property rights on the regulator's aggregate exploitation rate, we collected for each fishery in our data set, a history of management using the Catch Share database assembled by Environmental Defense Fund. In addition, we collected ecological characteristics including species-specific traits, as well as socioeconomic characteristics of the fishery (though these are limited given the scope of fisheries and time periods covered in the analysis). ${ }^{22}$ Our dataset classifies each fishery in each year as either a Catch Share or a non-Catch Share. While it might be possible to further delineate a suite of alternative management measures (e.g. differences in gear restrictions, season lengths, and licensing), we take a conservative approach and adopt a broad definition of Catch Shares (following Environmental Defense Fund (2012) and Melnychuk et al. (2012)). ${ }^{23}$ In so doing,

\footnotetext{
${ }^{19}$ Fishing mortality, $F_{i t}$, is the fraction of the resource stock that is harvested.

${ }^{20}$ For simplicity, we refer to $b_{i t}$ as "biomass" and to $h_{i t}$ as "harvest," keeping in mind that they are both scaled variables.

${ }^{21}$ This transformation allows us to estimate policy functions that directly coincide with the theoretical predictions. The bioeconomic formulation is the familiar Gordon-Schaefer model of renewable resources.

${ }^{22}$ In our preferred specifications, fishery-specific fixed effects are included, so time-invariant fisheries characteristics are not discussed further.

${ }^{23}$ We also include in our definition of "Catch Shares" any fisheries that are partially managed by Catch Shares as "treated." Any bias introduced in our definition of Catch Shares will make it less likely that we
} 
all fisheries not managed by some form of "Catch Share" are viewed as lacking strong property rights. We also note that, while there could be important differences between purely open access fisheries and fisheries managed by a regulator. All fisheries in our dataset have a total allowable catch (i.e. the aggregate exploitation rate) that is set by a regulator, so none of them are open access. This is in contrast to studies by Costello et al. (2008) and Heal and Schlenker (2008), who use all global fisheries (most of which are open access), to examine the impact of Catch Shares on fisheries collapse and harvest. Those authors find that fisheries with Catch Shares are less likely to collapse and ultimately attain higher catch rates, than do other fisheries. ${ }^{24}$

One potentially important empirical challenge is selection into treatment. While management may not be exogenously determined, in most cases the transition to property rightsbased management occurs due to changes in policy at a higher political level than the regulator herself. New Zealand's transition to Catch Shares in the 1980s, for example, was largely due to liberalization reforms taking place throughout government (Rees 2005). And in the United States, federal policies surrounding Catch Shares influenced the ability of individual fisheries to adopt Catch Shares. ${ }^{25}$ While there are regions that are more likely to have Catch Shares in our data, the timing of Catch Share adoption does not appear to be predictable in the panel, suggesting that the timing of selection into treatment is less of a concern. ${ }^{26}$ Our empirical strategy involves exploiting the rollout of Catch Share programs over time to identify the impact of property rights on exploitation.

Notably, the transition to Catch Shares does not appear to be correlated with the biological health of the fishery. Of the 178 fisheries in the data, 78 have transitioned to some form of Catch Share during the timeframe studied. Of those 78 fisheries, 44 transition to Catch Shares when relative biomass is low (i.e. $b_{i t}=\frac{B_{i t}}{B_{i}^{M S Y}}<1$ ), and 34 transition when relative biomass is high $\left(b_{i t}=\frac{B_{i t}}{B_{i}^{M S Y}}>1\right)$. Thus, the transition to Catch Shares does not appear to be systematically correlated with biomass levels or trends in exploitation leading up to the transition.

We begin by plotting the kernel densities of relative harvest for fisheries in the year 2005, a recent cross-section. The harvest rates between Catch Share and non-Catch Share fisheries appear different in a cross-section, with Catch Share fisheries tending to be more conservative in their aggregate harvest rates.

To begin, we show simple cross-sectional regression results for the most recent year in the data. The cross-sectional specification is given by

will find a significant effect, because we adopt the most liberal definition of a Catch Share.

${ }^{24}$ Key differences between our approach and these papers include: (1) we restrict attention to fisheries with a regulator (previous studies could not distinguish between non-Catch Share regulated fisheries and non-Catch Share open access fisheries), (2) we estimate out-of-equilibrium policy functions (which is possible because we have stock assessment data on the biomass), and (3) we provide a mechanism through which property right strength will affect a regulator's choice of harvest.

${ }^{25}$ For example, there was a (temporary) moratorium on new Catch Share programs in the United States until the Magnuson-Stevens Fishery Concservation and Management Act in 2006 (16 U.S.C. Â§Â§ 18011884).

${ }^{26}$ In the Appendix, we demonstrate that the observed independent variables in our data do a poor job at predicting the adoption of Catch Shares, and conditional on adoption, the timing of adoption is not explained by the fishery characteristics. 
Figure 3: Cross-Sectional Distribution of Relative Harvest for Catch Share and Non-Catch Share Fisheries

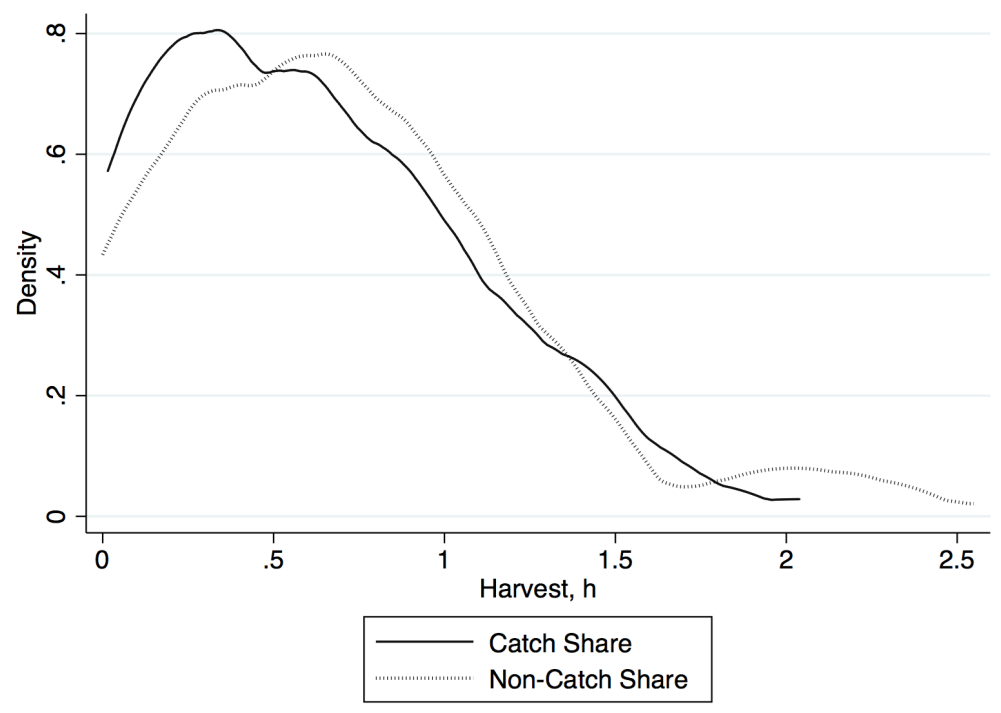

Notes: The figure shows the kernel density estimates for relative harvest (harvest/MSY) for the year 2005 for both Catch Share and Non-Catch Share fisheries.

$$
h_{i}=\alpha+\beta_{0} C S_{i}+\beta_{1} b_{i}+\beta_{2} C S_{i} * b_{i}+\varepsilon_{i},
$$

where $h_{i}$ is harvest in fishery $i, C S_{i}$ is an indicator for Catch Share management, and $b_{i}$ is biomass in fishery $i$. Alternative specifications use $\ln \left(h_{i}\right)$ as the dependent variable and include quadratic terms for biomass and interactions.

Results from this cross-sectional regression are shown in Table 1. They suggest that for the most current year in the data, Catch Share fisheries tend to be managed significantly more conservatively than non-Catch Share fisheries, providing some initial support for our theoretical predictions, though the result is not always statistically significant. The relative harvest in Catch Share fisheries is 0.2 units smaller than fisheries with comparable biomass levels (the reference level is $h=1$, where harvest equals the maximum sustained yield). This impact is dampened for higher levels of biomass, suggesting that as biomass increases, the average Catch Share fishery become less and less conservatively managed (as one might expect).

Ideally one would want to hold constant time-specific effects and fishery-specific differences, focusing only on differences in the timing of transition to Catch Shares. Our approach in the following section is non-parametric and relies on the difference in timing of the implementation of Catch Shares.

\subsection{Non-Parametric Approach}

We next take a nonparametric approach, looking for systematic deviations from the trend in harvest rates when Catch Shares are introduced. We restrict the sample here to fisheries that transition to Catch Shares at some point, exploiting the rollout in the timing of policy 
Table 1: Cross-Sectional Specifications: Impact of Catch Shares on Harvest Policy

\begin{tabular}{lcccc}
\hline & $(1)$ & $(2)$ & $(3)$ & $(4)$ \\
\hline \hline Dependent Variable & \multicolumn{2}{c}{$h_{i}$} & \multicolumn{2}{c}{$\ln \left(h_{i}\right)$} \\
\hline CS & $-0.199^{* *}$ & -0.1000 & -0.274 & -0.253 \\
& $(0.0959)$ & $(0.0683)$ & $(0.182)$ & $(0.182)$ \\
CS*b & 0.0324 & 0.168 & -0.0340 & $0.281^{* *}$ \\
& $(0.114)$ & $(0.110)$ & $(0.121)$ & $(0.135)$ \\
$\mathrm{CS}^{*} b^{2}$ & & $-0.107^{* *}$ & & $-0.134^{* *}$ \\
& & $(0.0437)$ & & $(0.0552)$ \\
$b$ & $0.199^{* * *}$ & $0.469^{* * *}$ & $0.407^{* * *}$ & $1.417^{* * *}$ \\
& $(0.0585)$ & $(0.155)$ & $(0.111)$ & $(0.276)$ \\
$b^{2}$ & & -0.0637 & & $-0.278^{* * *}$ \\
& & $(0.0486)$ & & $0.0649)$ \\
Constant & $0.503^{* * *}$ & $0.307^{* * *}$ & $-1.159^{* * *}$ & $-1.756^{* * *}$ \\
& $(0.0650)$ & $(0.0816)$ & $(0.171)$ & $(0.231)$ \\
Observations & 178 & 178 & 177 & 177 \\
R-squared & 0.173 & 0.239 & 0.131 & 0.231
\end{tabular}

Notes: An observation is at the fishery level for the most recent year available in the database. Heteroskedastic-robust standard errors are in parentheses; ***, and *** represent significance at the $10 \%$, $5 \%$ and $1 \%$ levels, respectively. The dependent variable is harvest (or the natural log of harvest). CS is a binary variable for Catch Share management, and $b$ is biomass.

change. Because the effect of Catch Shares on harvest rates may vary by fishery health, we separate the plots into "healthy" $\left(B>B^{M S Y}\right.$, so $\left.b>1\right)$ and "unhealthy" $(b<1)$ fisheries in the transition year. We then create indicator variables for Catch Share adoption in each year.

We restrict the sample to treated fisheries and regress $\ln (h)$ on fishery dummy variables, year dummy variables, and a set of dummies for the number of years until treatment. This allows us to nonparametrically examine at how exploitation rates change post-Catch Share adoption, holding constant period- and fishery-specific characteristics. The regression equation is given by:

$$
\ln \left(h_{i t}\right)=\theta_{i}+\lambda_{t}+\eta_{t-\tau_{i}}+\varepsilon_{i t}
$$

where $\tau_{i}$ is the year of ITQ adoption for fishery $i$.

Because of the number of fixed effects estimated to produce these plots, we do not show the results of these estimations here. Instead, we plot the coefficient estimates of the "event study" coefficients in Figure 4 separately for fisheries that are healthy and unhealthy at the time of transition to Catch Shares. The time scale is normalized so the transition occurs at date 0 . An advantage of this approach is that it is nonparametric, and we can examine differences in exploitation rates under different property rights regimes over time with few assumptions. The plots show the cohort annual averages after controlling for year and fishery-specific fixed effects.

For fisheries that are unhealthy at the time of adoption (top panel in Figure 4), we see that before Catch Shares, the exploitation rate is more-or-less constant. There is a slight, 
Figure 4: Coefficient Estimates for Catch Share Fisheries by Year-to-Adoption
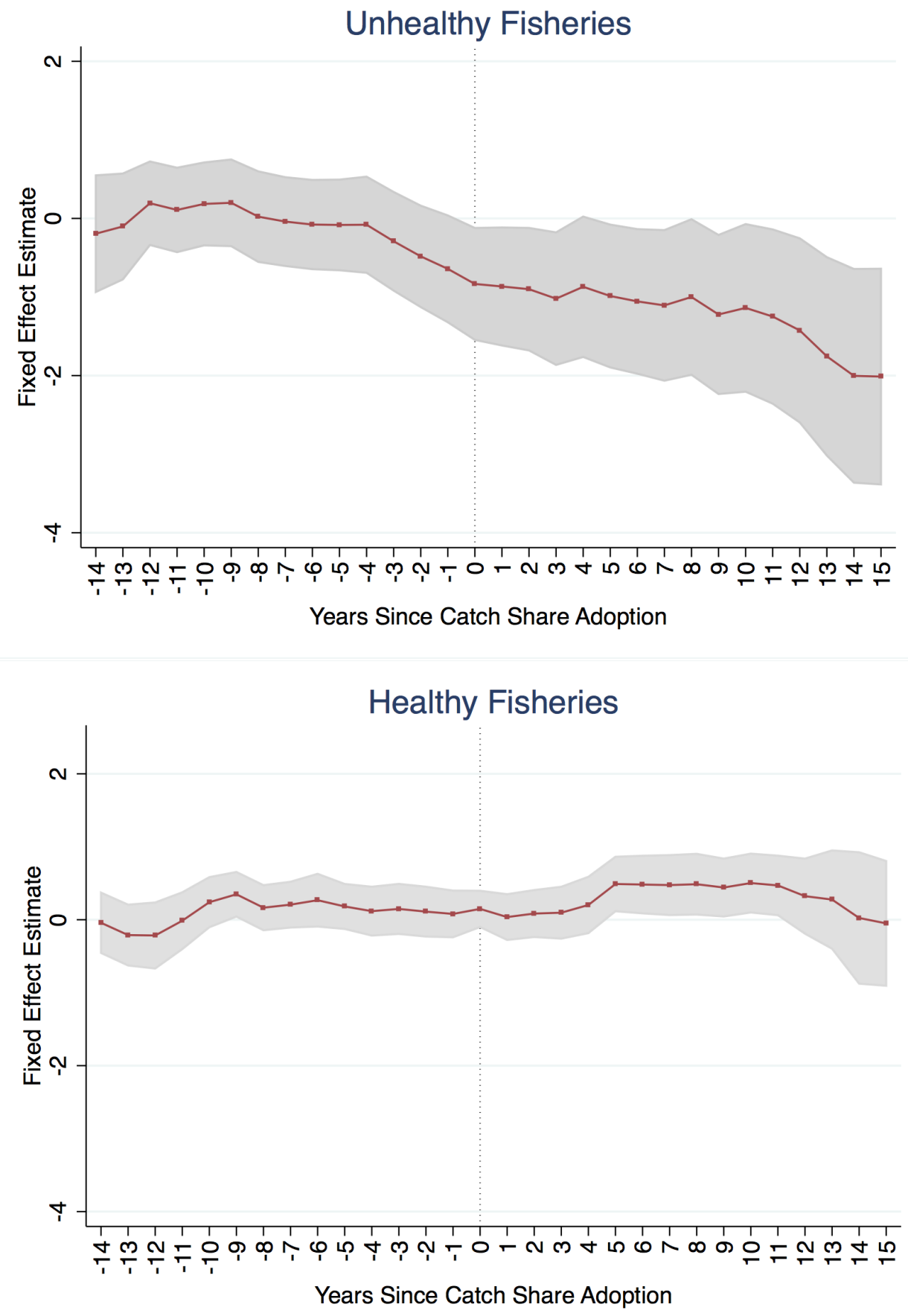

Notes: The figures above show the average effect of Catch Shares on exploitation for Catch Shares adopted in different year cohorts, shown separately for "unhealthy" vs. "healthy" stocks at the time of policy change. The dependent variable is harvest. The variable "years since Catch Share adoption" represents the number of years for that specific Catch Share cohort. The sample is restricted to include only fisheries that adopt Catch Shares at some time in the data. The vertical axis represents the coefficients on the cohort-by-year interactions. 
insignificant drop in exploitation in the few years prior to Catch Share implementation. This is unsurprising, as policy changes are generally determined a few years in advance, so stock rebuilding efforts could begin before Catch Shares are officially introduced. Postimplementation (marked by $t=0$ on the horizontal axis), there is a significant drop in aggregate harvest. This is consistent with our theoretical prediction that the introduction of property rights will lead to a lower aggregate harvest rate.

The plot for fisheries that were healthy at the time of transition (bottom panel of Figure 4) looks somewhat different. Before transition, harvests were relatively constant. After the transition to Catch Shares, harvests increase slightly (likely a movement toward the economically-efficient level of exploitation if biomass levels are sufficiently high).

An advantage to this nonparametric approach is that it allows us to uncover trends in exploitation for different cohorts of Catch Share fisheries, exploiting the timing in adoption. In the next section we estimate the complete policy functions directly; this will allow us to directly test the theoretical predictions above.

\subsection{Policy Function Estimates}

Since observations from the stock assessment data are at the fishery-year level, we can exploit the panel nature of the data (especially the rollout of Catch Shares over space and time) to estimate the impact of Catch Shares on the harvest policy function, controlling for fishery-specific characteristics. As discussed in the Appendix, predicting the timing of Catch Share adoption is difficult, and it appears to be unrelated to biomass or other observable characteristics.

We assume that the policy $\left(h_{i t}\right)$ is a function of the resource stock $\left(b_{i t}\right)$, property right strength $\left(C S_{i t}\right)$, and a set of time invariant fixed effects as well as common contemporaneous shocks. This approach will allow us to estimate the implied policy function pursued by the fishery regulator, and to determine if and how the presence of Catch Shares affects that policy function.

The most basic specification is to regress $h$ on $b$, an indicator for Catch Shares, and interaction terms. This allows (but does not require) a regulator's policy to be state-dependent. ${ }^{27}$ We include fishery and year fixed effects to allow for unobserved heterogeneity in regions and/or time periods. Consequently, we do not include time-invariant fishery-specific characteristics such as species traits. The baseline fixed-effects specification is given by

$$
h_{i t}=\alpha * C S_{i t}+\beta * b_{i t}+\gamma * C S_{i t} * b_{i t}+\phi_{i}+\theta_{t}+\varepsilon_{i t}
$$

where $h_{i t}$ is harvest for fishery $i$ in year $t$; $C S_{i t}$ is an indicator for Catch Share management in fishery $i$ in year $t$; and $b_{i t}$ is biomass in that fishery and year. Alternative specifications include quadratic terms in biomass (and interactions) and use $\ln \left(h_{i t}\right)$ as the dependent variable.

Results of the fixed effects specifications are shown in Table 2. Specifications in columns (1) through (4) take $h_{i t}$ as the dependent variable, and (5) through (8) use $\ln \left(h_{i t}\right)$. Results are generally consistent with our main theoretical prediction: Catch Shares (i.e. strong

\footnotetext{
${ }^{27}$ In addition, there may be some "policy momentum," where there is autocorrelation. We allow for this possibility, conducting inference using Newey-West standard errors.
} 


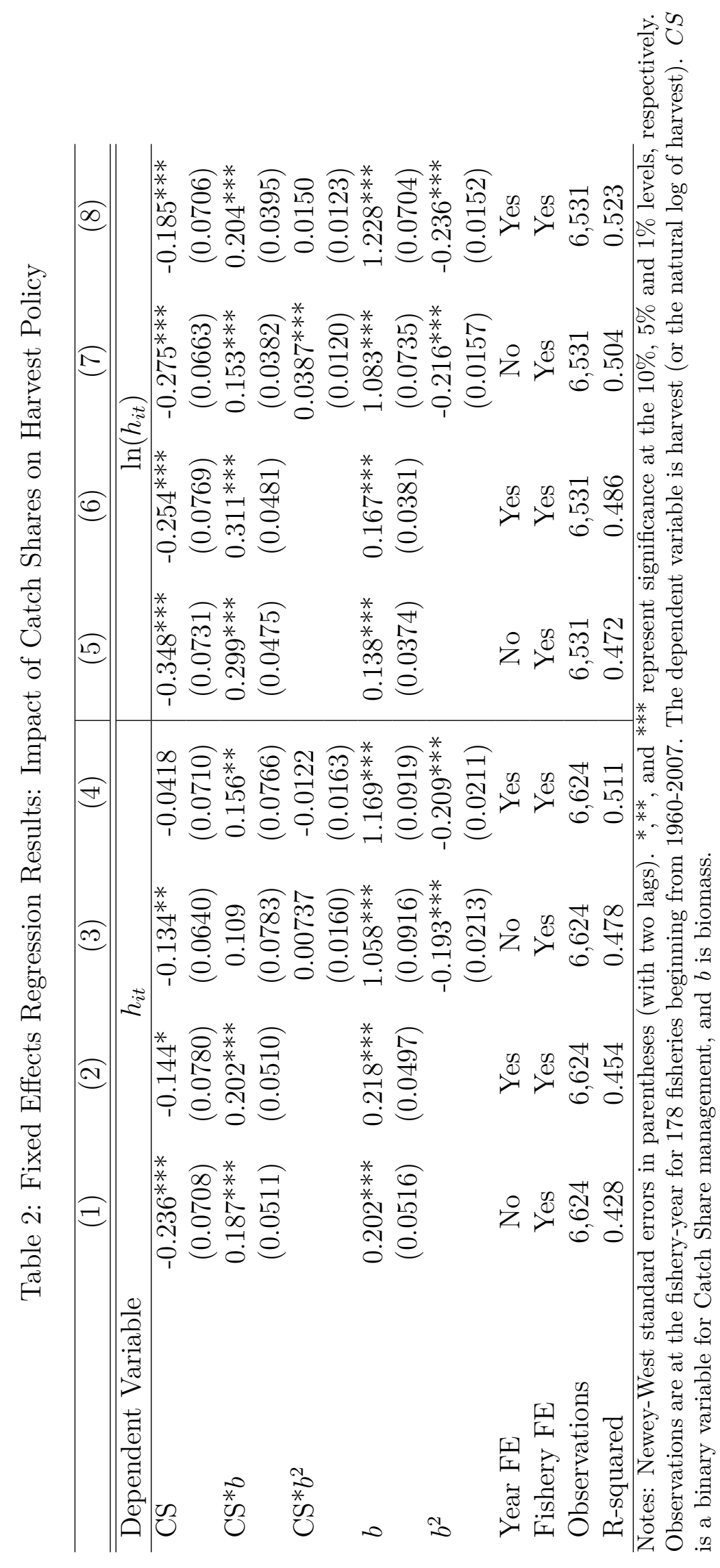


property rights) lead to more conservative harvest. The negative coefficient on $C S$ indicates that the transition to Catch Shares is marked by a significant decrease in the exploitation rate, which suggests that, at least for low levels of biomass, Catch Shares lead to significantly more conservative harvest policy.

Our theoretical prediction that policy functions are upward-sloping in biomass is robustly confirmed, as higher biomass levels lead to higher harvest across specifications. The results also indicate that as biomass becomes large, the difference between harvest under Catch Share and non-Catch Share fisheries starts to decrease. Indeed, for most specifications, the point estimates suggest that Catch Share fisheries have more aggressive harvest policies when biomass is very high. At very high levels of biomass, the socially optimal policy would generally be to harvest down the stock rapidly; our empirical results (for which Catch Sharemanaged fisheries have a higher harvest when biomass is large) support this expectation, though this result is not statistically significant. In general, these results provide strong evidence in support of our theoretical predictions, particularly for unhealthy fisheries (i.e. those in need of rebuilding).

\subsection{Policy Functions and Fishery Biology}

Our empirical estimates can be used to directly plot the harvest policy functions relative to the biology of the fishery. From a standard Gordon-Schaeffer model of a renewable resource, the biological steady state is:

$$
H=\phi B(1-B / K)
$$

where $H$ is harvest, $B$ is biomass and $\phi$ and $K$ are parameters for intrinsic growth and carrying capacity, respectively. Again letting $M S Y$ stand for maximum sustained yield, from this equation we can derive:

$$
\begin{array}{r}
M S Y=\phi K / 4 \\
B^{M S Y}=K / 2
\end{array}
$$

Letting $h \equiv H / M S Y$ and $b \equiv B / B^{M S Y}$ as before, we can rewrite Equation 25 as follows:

$$
h=2 b(1-b / 2)
$$

Notably, this biological steady state equation is independent of both $\phi$ and $K$ so the normalization effectively scales out fishery specific growth parameters, conveniently facilitating comparisons across very different kinds of fisheries. Thus we can plot the biological steady states and the policy functions in the same space to determine the different implied equilibria under Catch Share and non-Catch Share management.

We plot the policy functions for two fisheries in Figure 5. We use the fixed effects specifications with quadratic biomass terms (and interactions with $C S$ ) to plot policy functions in $(b, h)$ space. This shows the harvest policy (for a given fishery and average year) for Catch Share and non-Catch Share fisheries. 
Figure 5: Examples of Estimated Policy Functions by Property Right Type

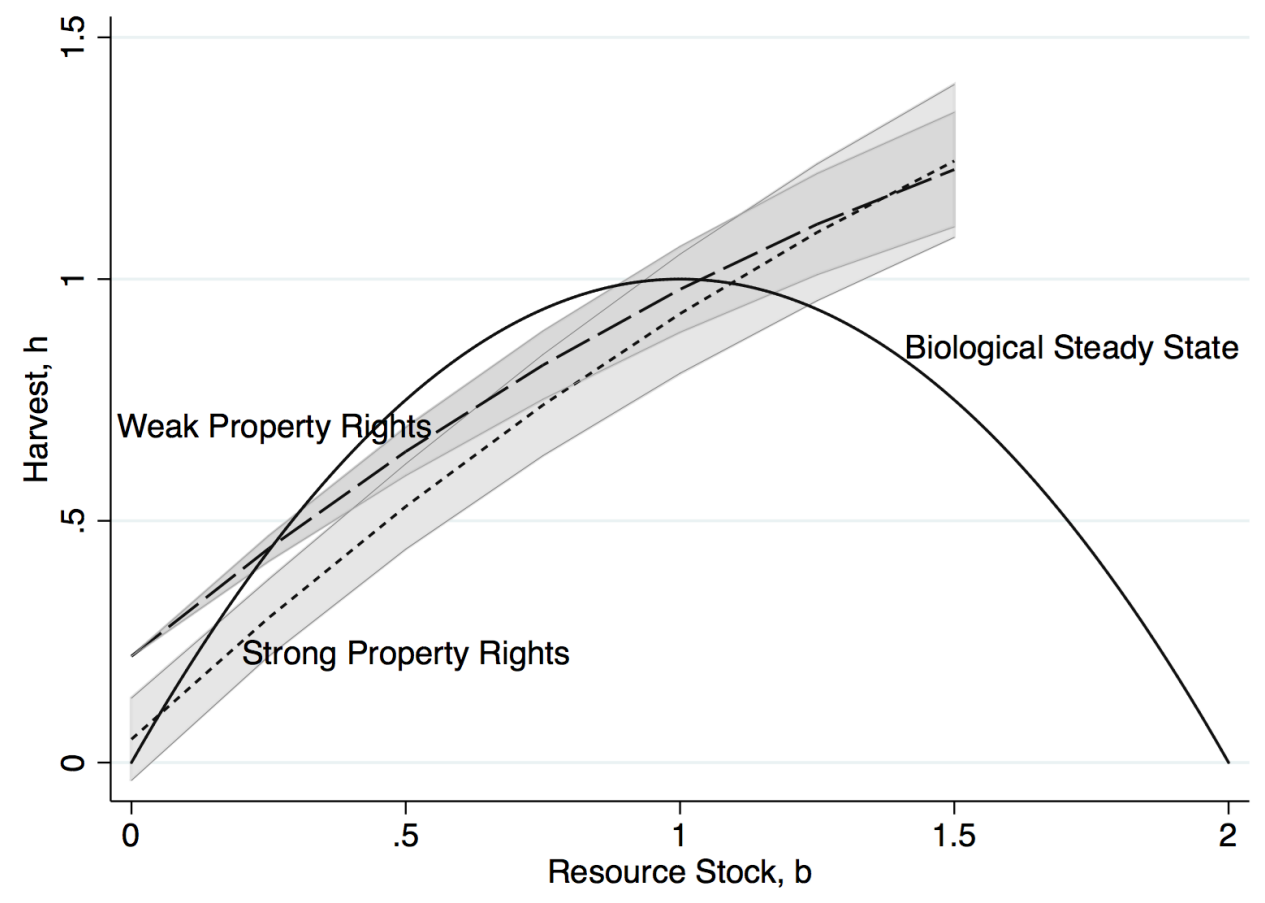

(a) Median Fishery

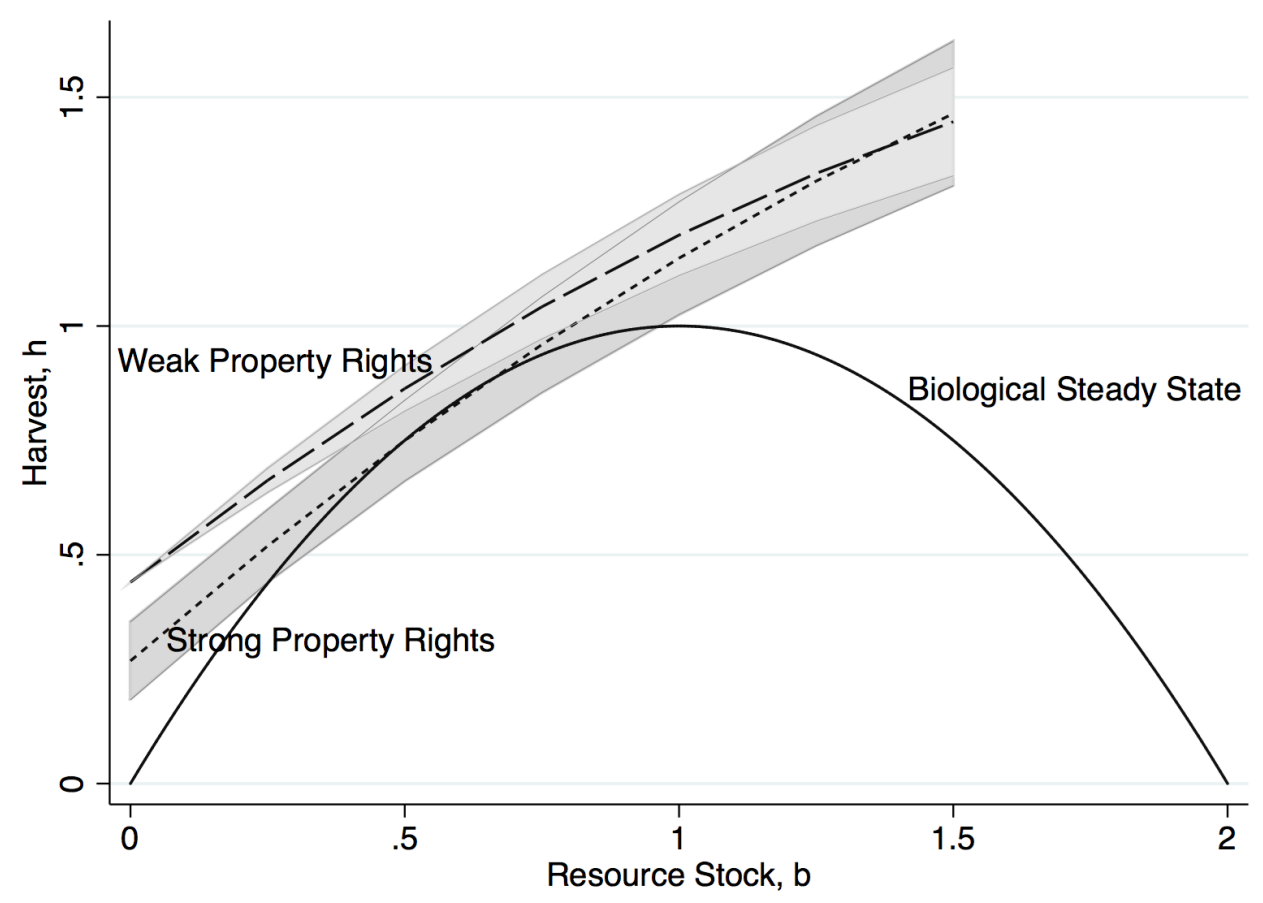

(b) Top Tertile Fishery

Notes: Estimated policy functions and the 95\% confidence intervals are plotted for Catch Share and nonCatch Share fisheries over a range of biomass. The constants included are point estimates corresponding to fisheries with the median and top tertile fixed effects, respectively. 
The top figure uses a linear fixed effects specification and shows the estimated policy function for the median fishery fixed effect. The bottom figure is the analogous plot using the top tertile fishery fixed effect. Across the alternative specifications we see that Catch Shares seem to promote conservation, particularly when biomass is low. As biomass becomes more plentiful, the difference between the policy functions becomes statistically insignificant, though the point estimates still suggest that Catch Shares are more conservative until biomass exceeds the biomass level corresponding to maximum-sustained yield.

Interestingly, for the fisheries with the largest fixed effects (bottom panel of Figure 5), the policy function for non-Catch Share fisheries lies everywhere above the biological steady state. This suggests that for those fisheries, the non-Catch Share policy is unsustainable in the long-run and would eventually lead to stock collapse, or in the extreme case, extinction if the harvest policy remains unchanged.

\section{Conclusion}

One of the most fundamental insights from political economy is that strong, secure property rights can induce more efficient resource use. Indeed, the literature has demonstrated a large, significant impact of property rights on economic outcomes, including natural resource extraction. But most of the existing empirical and theoretical evidence regards individual incentives: When the underlying property rights are weak, a bird in the hand is worth two in the bush, so individuals have an incentive to overexploit a common pool resource. However, the literature has largely ignored the fact that for many natural resources, it is a regulator, not individual firms, who determines the allowable extraction rate. With this in mind, we introduce a regulator into a natural resource extraction model and demonstrate that under stronger property rights, individuals have an incentive to lobby for a lower extraction rate. The regulator, who balances the interests of current and (potential) future resource users, is "captured" by resource users, regardless of property rights strength. When property rights are strong, current and future resource users are one-in-the-same, so the regulator's choice is consistent with the maximization of the resource's value. But when resource users have insecure rights, our model predicts that the captured regulator will allow inefficiently high extraction rates.

A few extensions to the model are worth noting. First, in addition to the choice of the aggregate harvest rate, it is conceivable that the regulator could influence the probability of revocation itself. In our model it can easily be shown that, if future resource owners have less influence over the regulator do than current owners (i.e. $\gamma<1$ ), the regulator would choose strong property rights (i.e. zero probability of revocation). That is, the value of $\theta$ that maximizes the value of the resource will be zero. ${ }^{28}$ We have also abstracted away from the issue of who the next owner will be, should the rights of current owners be revoked, which will surely depend on political considerations that are outside of our model. If the regulator could choose, she would (under reasonable conditions) like to return the rights back to the

\footnotetext{
${ }^{28}$ To see this, simply note that by definition $\gamma<1$ implies that the welfare of future resource owners is given less weight than the welfare of current owners. Furthermore, current owners are strictly better off by maintaining ownership of harvest rights. Therefore current owners would exert pressure on the regulator to choose strong property rights, given here by a zero hazard.
} 
incumbent. $^{29}$

The key prediction from our model is that strong individual property rights will cause the regulator to manage the resource more conservatively. We tested this prediction empirically using a novel dataset spanning nearly 200 large, commercial fisheries around the world. Nearly half of the fisheries in the data have transitioned to some version of a Catch Share during the past thirty years. We exploit the change in property rights to test whether fisheries that transition to the strong property rights approaches are managed more conservatively than are similar fisheries managed with weaker property rights. We find a significant, negative impact of property rights on overall exploitation rates in fisheries. This impact is most pronounced for low levels of biomass, suggesting that property rights could play a significant role in facilitating the recovery of a collapsed fishery. That is, the introduction of a Catch Share leads to a significantly lower aggregate exploitation rate. Because harvest is determined by a regulator in all fisheries in our dataset, we argue that differences in exploitation rates can be explained by different incentives for regulatory capture.

A few caveats will suggest fruitful areas for further research. First, while we have used a coarse measure of property right strength (the presence or absence of Catch Shares), future work may be able to tease apart a more nuanced story about the features of a property right system that change incentive sufficiently to alter observed exploitation rates. Second, we have assumed that the most important pathway through which property rights affect exploitation rates is through regulatory capture. It is also possible that pecuniary effects (such as increases in price or decreases in cost) also accrue as a consequence of strong property rights; these effects may also motivate policy changes. ${ }^{30}$ Finally, we have argued that regulatory capture exists in all fisheries and have examined its consequences following the transition to strong property rights. But it is possible that the extent of regulatory capture also depends on property right strength. To our knowledge, this issue has not been explored theoretically or empirically, but could be approached using a framework such as the one developed here.

These caveats notwithstanding, our results demonstrate that the strength of property rights to individual firms can impact aggregate harvest policy, even when extraction is determined by a regulator. It has been widely held that individual property rights will lead to more efficient harvest behavior by individuals, but our model and results suggest that the regulator's behavior also changes as a consequence of individual property rights.

\section{References}

Acemoglu, D. and S. Johnson (2005). Unbundling institutions. Journal of Political Economy 113(5), 949-995.

\footnotetext{
${ }^{29}$ To see this, suppose that the probability of revocation $(\theta)$ is fixed. If the regulator can choose how rights will be reallocated after expropriation, then her objective function would be maximized by giving rights back to current owners if $\gamma<1$. If all owners, current and future, have the same influence over the regulator (i.e. $\gamma=1$ ), then the regulator would be indifferent between giving the resource rights back to its current owners or reallocating among some new set of users.

${ }^{30}$ Though both of these effects would (under reasonable conditions) cause the regulator to increase extraction rates, so this observation seems to further strengthen our regulatory capture finding.
} 
Alston, L., G. Libecap, and B. Mueller (2000). Land reform policies, the sources of violent conflict, and implications for deforestation in the Brazilian Amazon. Journal of Environmental Economics and Management 39(2), 162-188.

Arnason, R. (2012). Property rights in fisheries: How much can individual transferable quotas accomplish? Review of Environmental Economics and Policy 6(2), 217-236.

Bailey, M. J. (2012). Reexamining the impact of family planning programs on us fertility: evidence from the war on poverty and the early years of Title X. American Economic Journal. Applied Economics 4 (2), 62.

Besley, T. (1995). Property rights and investment incentives: Theory and evidence from Ghana. Journal of Political Economy 103(5), 903-937.

Bohn, H. and R. Deacon (2000). Ownership risk, investment, and the use of natural resources. American Economic Review 90(3), 526-549.

Boscolo, M. and J. R. Vincent (2000). Promoting better logging practices in tropical forests: A simulation analysis of alternative regulations. Land Economics 76(1), pp. $1-14$.

Costello, C., S. Gaines, and J. Lynham (2008). Can catch shares prevent fisheries collapse? Science 321(1678-1681).

Costello, C. and D. Kaffine (2008). Natural resource use with limited tenure property rights. Journal of Environmental Economics and Management 55(1), 20-36.

Deacon, R. (1995). Assessing the relationship between government policy and deforestation. Journal of Environmental Economics and Management 28, 1-18.

Deacon, R. (1999). Deforestation and ownership: Evidence from historical accounts and contemporary data. Land Economics 71 (3).

Environmental Defense Fund (2012). Catch share fisheries and resources. Technical report.

Gauvin, J. R., J. M. Ward, and E. E. Burgess (1994). Description and evaluation of the wreckfish (polyprion americanus) fishery under individual transferable quotas. Marine Resource Economics 9(2), 99-118.

Grafton, Q., D. Squires, and K. J. Fox (2000). Private property and economic efficiency: A study of a common-pool resource. Journal of Law and Economics 43(2), 679-714.

Grafton, R. Q., R. Arnason, T. Bjørndal, D. Campbell, H. F. Campbell, C. W. Clark, R. Connor, D. P. Dupont, R. Hannesson, R. Hilborn, et al. (2006). Incentive-based approaches to sustainable fisheries. Canadian Journal of Fisheries and Aquatic Sciences 63(3), 699-710.

Grainger, C. and C. Costello (2014). Capitalizing property rights insecurity in natural resource assets. Journal of Environmental Economics and Management 67(2), 224-40.

Grainger, C. and D. Parker (2013). The political economy of fishery reform. Annual Reviews of Resource Economics 5(1), 369-386.

Heal, G. and W. Schlenker (2008). Economics: sustainable fisheries. Nature 455(7216), 1044-1045. 
Hilborn, R., J. L. Orensanz, and A. M. Parma (2005). Institutions, incentives and the future of fisheries. Philosophical Transactions of the Royal Society B: Biological Sciences 360(1453), 47-57.

Homans, F. R. and J. E. Wilen (1997). A model of regulated open access resource use. Journal of Environmental Economics and Management 32(1), 1-21.

Hoynes, H. W. and D. W. Schanzenbach (2009). Consumption responses to in-kind transfers: Evidence from the introduction of the food stamp program. American Economic Journal: Applied Economics 1(4), 109-139.

Johnson, R. and G. D. Libecap (1982). Contracting problems and regulation: The case of the fishery. American Economic Review, 1005-1022.

Karpoff, J. (1987). Suboptimal controls in common resource management: the case of the fishery. The Journal of Political Economy, 179-194.

Leal, D. R., M. De Alessi, and P. Baker (2005). The ecological role of IFQs in US fisheries. Bozeman, MT: Property and Environment Research Center.

Liscow, Z. D. (2013). Do property rights promote investment but cause deforestation? quasi-experimental evidence from nicaragua. Journal of Environmental Economics and Management 65(2), 241-261.

Melnychuk, M., T. Essington, T. Branch, S. Heppell, O. Jensen, J. Link, S. Martell, A. Parma, J. Pope, and A. Smith (2012). Can catch share fisheries better track management targets? Fish and Fisheries 13(3), 267-290.

Mid-Atlantic Fishery Management Council (1985). Amendment 6 to the Fishery Management Plan for Atlantic Surf Clam and Ocean Quahog Fisheries. Technical report.

Mid-Atlantic Fishery Management Council (2012, June). Committee meeting, memorandum. Technical report.

New England Fishery Management Council (1984). Amendment 4 to the Fishery Management Plan for Atlantic Surf Clams and Ocean Quahogs. Technical report.

Newell, R., J. Sanchirico, and S. Kerr (2005). Fishing quota markets. Journal of Environmental Economics and Management $49(3), 437-462$.

North, D., J. J. Wallis, and B. R. Weingast (2009). Violence and social orders: a conceptual framework for interpreting recorded human history. Cambridge University Press.

Okey, T. A. (2003). Membership of the eight regional fishery management councils in the united states: are special interests over-represented? Marine policy 27(3), 193-206.

Peltzman, S. (1976). Toward a more general theory of regulation. Journal of Law and Economics 19, 211-248.

Posner, R. (1974). Theories of economic regulation. Bell Journal of Economics and Management Science 5(2), 335-358.

Rees, E. (2005). In what sense a fisheries problem? negotiating sustainable growth in New Zealand's fisheries. PhD Dissertation, University of Auckland. 
Stigler, G. (1971). The theory of economic regulation. Bell Journal of Economics and Management Science 2, 3-21. 


\section{A Predicting Catch Shares and Timing of Adoption}

There could be concern about endogenous treatment, as individual fisheries could influence whether or not Catch Shares are implemented. In this appendix we show specifications that use our observed data to predict 1) whether a fishery eventually adopts Catch Shares, and 2) the timing of adoption. We find that these are unlikely to pose an endogenous treatment concern in the fishery setting.

We follow the approach of Hoynes and Schanzenbach (2009) and Bailey (2012) by choosing covariates in a pre-treatment year (1980) to predict whether a fishery eventually adopts Catch Shares. We then use those variables to predict the number of years to adoption. We include Large Marine Ecosystem (LME) fixed effects in some specifications, as well as measures of the characteristics of the species in a fishery (namely the carrying capacity, $K$, and the maximum length, $L_{\infty}$, from a von Bertalanffy growth model, and the trophic level of the species). Some of these variables are not available for all fisheries in the dataset, so we restrict the sample to the fisheries with these independent variables.

In the first two columns of Table A.1, we show estimates from a linear probability model of whether a fishery eventually adopts Catch Shares. The variables are generally insignificant. Adding LME fixed effects improves the predictive power of the model, and 7 of the 20 LME coefficients are significant at the $5 \%$ level. This is driven by the fact that some regions were more likely to adopt Catch Shares due to country-level characteristics. We note that our empirical specifications in the main text include fishery-level fixed effects, so these characteristics are held constant in our main results.

The last two columns show OLS estimates of the timing of Catch Share adoption. Conditional on eventually adopting Catch Shares, the dependent variable is the number of years (from 1980) until the fishery adopts Catch Shares. While it is clear empirically that an individual fishery does not transition to Catch Shares only when its biomass is critically low (half of the fisheries transition to Catch Shares when relative biomass is high), these results suggest that the observable characteristics in a pre-treatment year do a poor job of predicting the adoption of Catch Shares. 
Table A.1: Selection into Treatment? Predicting Catch Share Adoption

\begin{tabular}{|c|c|c|c|c|}
\hline \multirow[b]{2}{*}{ Dependent Variable } & \multirow{2}{*}{\multicolumn{2}{|c|}{ (1) $(2)$}} & \multirow{2}{*}{\multicolumn{2}{|c|}{$\begin{array}{l}(3) \\
\text { Years to Adoption }\end{array}$}} \\
\hline & & & & \\
\hline Relative Biomass in 1980 & $\begin{array}{c}0.0459 \\
(0.0391)\end{array}$ & $\begin{array}{c}0.0256 \\
(0.0565)\end{array}$ & $\begin{array}{c}0.587 \\
(1.128)\end{array}$ & $\begin{array}{c}1.354 \\
(1.156)\end{array}$ \\
\hline Relative Harvest in 1980 & $\begin{array}{c}-0.0615^{* * * *} \\
(0.0207)\end{array}$ & $\begin{array}{l}-0.0146 \\
(0.0158)\end{array}$ & $\begin{array}{l}-0.753 \\
(1.165)\end{array}$ & $\begin{array}{l}-0.967 \\
(0.859)\end{array}$ \\
\hline von Bertalanffy $K$ & $\begin{array}{c}-0.102 \\
(0.454)\end{array}$ & $\begin{array}{c}0.417 \\
(0.360)\end{array}$ & $\begin{array}{c}0.320 \\
(10.86)\end{array}$ & $\begin{array}{l}-2.383 \\
(8.561)\end{array}$ \\
\hline von Bertalanffy $L_{\infty}$ & $\begin{array}{r}-0.000120 \\
(0.00103)\end{array}$ & $\begin{array}{l}-0.000371 \\
(0.000958)\end{array}$ & $\begin{array}{c}-0.0783^{* * * *} \\
(0.0266)\end{array}$ & $\begin{array}{r}-0.0474^{*} \\
(0.0245)\end{array}$ \\
\hline Trophic Level & $\begin{array}{l}-0.00919 \\
(0.0900)\end{array}$ & $\begin{array}{c}0.0769 \\
(0.0718)\end{array}$ & $\begin{array}{l}3.318^{* *} \\
(1.272)\end{array}$ & $\begin{array}{c}0.443 \\
(1.215)\end{array}$ \\
\hline Constant & $\begin{array}{l}0.666^{*} \\
(0.358)\end{array}$ & & $\begin{array}{c}8.882 \\
(7.210)\end{array}$ & \\
\hline LME Fixed Effects & No & Yes & No & Yes \\
\hline Number LMEs & & 20 & & 16 \\
\hline Significant LMEs (5\%) & & 7 & & 7 \\
\hline F-Stat p-value (joint significance of LMEs) & & 0.000 & & 0.000 \\
\hline R-squared & 0.065 & 0.534 & 0.171 & 0.757 \\
\hline Observations & 115 & 113 & 68 & 68 \\
\hline
\end{tabular}

Notes: The dependent variable in the first two columns is an indicator variable for whether a fishery eventually adopts Catch Shares in our data. The results in the first two columns are from a linear probability model. The dependent variable in (3) and (4) is the number of years from 1980 to the adoption of Catch Shares for a fishery, and the regression is estimated with OLS. Standard errors in parentheses are heteroskedastic-robust. ***,**, and ${ }^{*}$ represent significance at the $1 \%, 5 \%$, and $10 \%$ levels, respectively. 